\title{
Another look at age trends in the Poggendorff illusion: Real or illusory?
}

\author{
SUZANNE GREIST-BOUSQUET \\ Kean College of New Jersey, Union, New Jersey \\ JANET DAVIS \\ Drew University, Madison, New Jersey \\ and \\ H. R. SCHIFFMAN \\ Rutgers, The State University, New Brunswick, New Jersey
}

\begin{abstract}
Girgus and Coren (1987) recently reported different age trends for the Poggendorff illusion as a function of parametric manipulations of the figure. In brief, they found that figural variations that produce the largest Poggendorff illusion decrease in magnitude with age. We comment on and augment their developmental findings with two experiments and report on select amputations of the Poggendorff figure and an alternative measure of the Poggendorff illusion.
\end{abstract}

The Poggendorff illusion offers two different ways to assess illusion magnitude. One way is to measure the magnitude of apparent noncollinearity of the diagonal segments or transversals (see Girgus \& Coren, 1987; Leibowitz \& Gwozdecki, 1967). An alternative and perhaps more fundamental assessment technique requires subjects to judge the intertransversal extent. An increasing body of research (Greist-Bousquet \& Schiffman, 1981, 1985, 1986; Pressey, 1971; Quina-Holland, 1977; Zanuttini, 1976) suggests that an underestimation of the interior extent promotes, or at least contributes to, the misalignment in the Poggendorff illusion. It is therefore of interest to examine age trends in judgments of intertransversal extent. It is also of interest to examine these age trends in select amputated variations of the Poggendorff figure, since judged interior extent systematically differs as a function of the type of parallel components present in the figure (Greist-Bousquet \& Schiffman, 1981; Judd, 1899; Quina-Holland, 1977; Weintraub \& Tong, 1974; Zanuttini, 1976).

In both experiments described here, second, fourth, sixth, and eighth graders were tested. The children were students from two schools in the central New Jersey area. All children had 20/20 corrected or uncorrected visual acuity.

In Experiment 1, 20 children from each class re-created on paper the intertransversal extent in the classic (Inset A of Figure 1), obtuse-angle (Inset B of Figure 1), and acute-angle (Inset $\mathrm{C}$ of Figure 1) variations of the Pog-

This research was supported by funds from the Research Council of Rutgers, The State University to H. R. Schiffman. The authors wish to thank Michael Ferrari for his invaluable assistance. Requests for reprints should be sent to S. Greist-Bousquet, Department of Psychology, Kean College of New Jersey, Union, NJ 07083. gendorff figure. Children also re-created the interior extent in a transversal-only control figure (Inset D of Figure 1). The dimensions of the Poggendorff variations and the paper-and-pencil method used are described fully by Greist-Bousquet and Schiffman (1981).

Figure 1 shows the mean judged extent for each Poggendorff variation as a function of grade level. The analysis of variance requirement of homogeneity of variance could not be met with the acute-angle variation. This, of course, is not very surprising in developmental data involving judgments of this nature. Therefore, the acuteangle variation was excluded from the analysis. Based on an analysis of the other variations, the effect of age was not significant $[F(3,76)=.028, p>.05]$. No significant differences were found between the three figures $[F(2,152)=.060, p>.05]$. The interaction also was not significant $[F(6,152)=1.010, p>.05]$.

The results indicate that interior linear distortion within the classic Poggendorff figure and its obtuse-angle variation is not different across different ages. Consistent with previous findings with college students (GreistBousquet \& Schiffman, 1981), general differences can be observed between judgments on the acute-angle variation and judgments on other variations of the Poggendorff illusion. However, previous findings included differences between the classic and obtuse-angle variations and the transversal-only control figure. The absence of this difference here is puzzling. The variability of the data may provide a clue: perhaps children's knowledge of task requirements changes as a function of age. In Experiment 2, this was addressed directly, and considerable effort was made to increase the clarity of the instructions for children.

Eighteen subjects from each grade were asked to imagine that the Poggendorff's left transversal segment was 


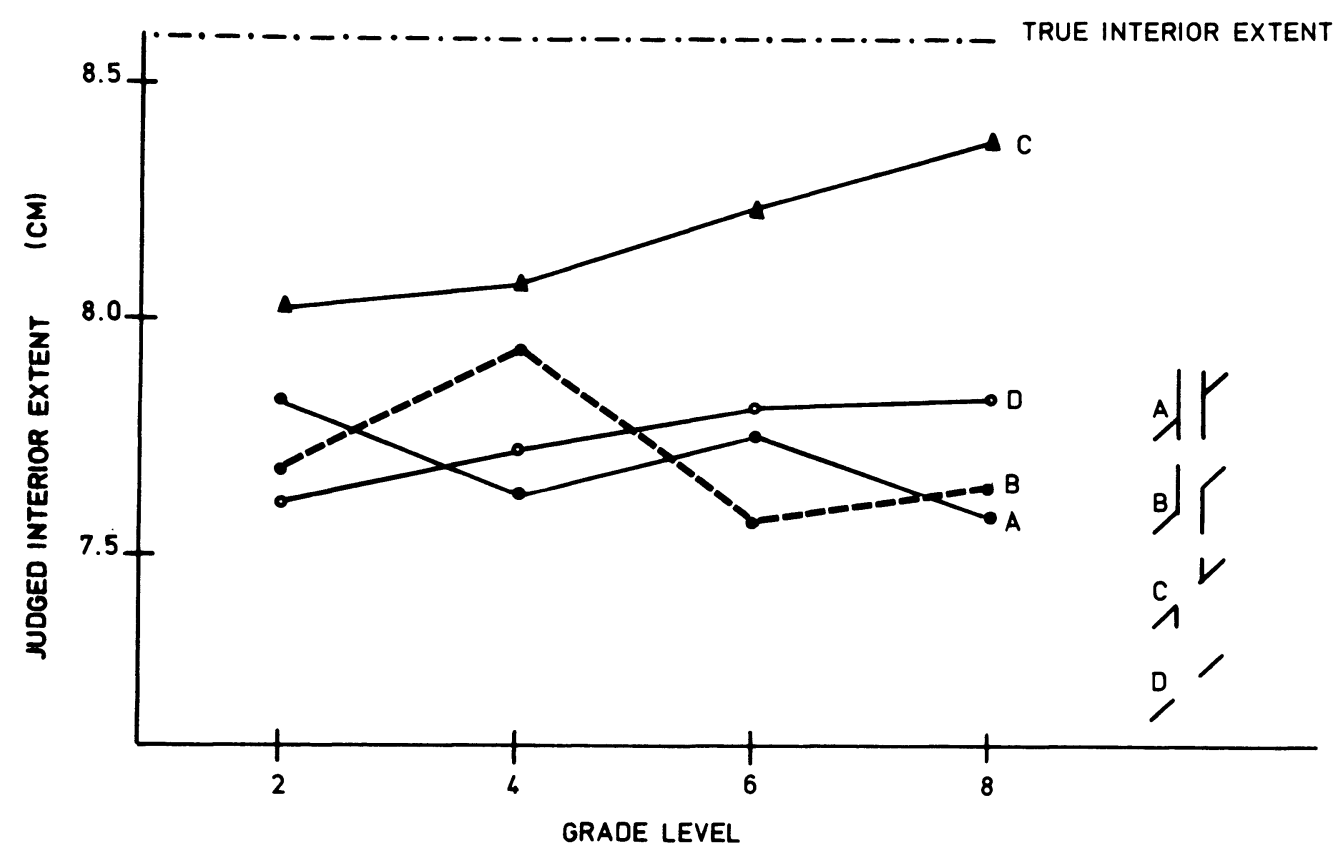

Figure 1. Experiment 1: age trends in mean judged extent for Poggendorff variations.

a train track that continued under a wide wall. In fact, the transversal was modified to two parallel lines, and the vertical parallels ( $1 \mathrm{~mm}$ thick) were connected with horizontal lines as seen in the inset of Figure 2. The angle of the transversals and the intertransversal extent was identical to that of Experiment 1 and to that of a previous study (Greist-Bousquet \& Schiffman, 1981). Subjects were asked to pencil a mark on the right vertical parallel where the tracks on the left would emerge from the tunnel in the wall. Subjects also re-created the intertransversal extent in the classic figure and the transversal-only control figure. For these figures, subjects were asked to re-create the amount of track needed to finish the tracks.

Mean values of judged extent are plotted in Figure 2 as a function of grade level. An analysis of variance performed on the extent judgments yielded a significant age effect $[F(3,68)=17.816, p<.001]$. The difference between figures was found to be significant $[F(1,68)=$ $21.199, p<.001]$; the interaction was not significant $[F(3,68)=.460, p>.05]$.

Although there appears to be a significant age trend in this experiment, we would argue that the magnitude of the Poggendorff illusion does not vary with the viewer's age; rather, what differs with age is the ability to make extent judgments in a diagonal orientation. This interpretation is supported by the finding that although there is a significant underestimation in the classic figure when compared with the control, the difference does not change as a function of age (i.e., the interaction is not significant). It is also of interest to note that mean extent judgments for eighth graders are very similar to those observed for college students (Greist-Bousquet \& Schiffman, 1981); these data are provided in Figure 2 for comparison.

Misalignment data from this experiment showed large variability. Various measures of the magnitude of misalignment (e.g., deviations from objective collinearity and intertransversal extent estimates) yield stable estimates in adults, yet all were found to be heterogeneous in variance. Although statistically unanalyzed, Poggendorff misalignment presented as mean intertransversal extent judgments is provided in Figure 2.

The present finding of an absence of any age trend for Poggendorff misalignment or interior underestimation conflicts with results of previous work (Girgus \& Coren, 1987; Leibowitz \& Gwozdecki, 1967). Girgus and Coren's interpretation suggests that the dimensions of the illusion figures used in the present study may not have been sufficiently powerful to produce significant age trends. The age trends that they report are for variations of the Poggendorff illusion that include the most extreme transversal angles and the largest parallel separations. In both types of Poggendorff variations, alignment of transversal segments must occur over great intertransversal distancesperhaps a difficult task for younger children. Clearly, Girgus and Coren's data would be more persuasive if transversal-only controls were used to assess children's alignment abilities across ages.

Another possibility that cannot be ruled out on the basis of Girgus and Coren's (1987) report is that the discrepancy is due to the present criterion of homogeneity of variance for illusion measures. Previous findings of declining illusion susceptibility with age may indicate chil- 


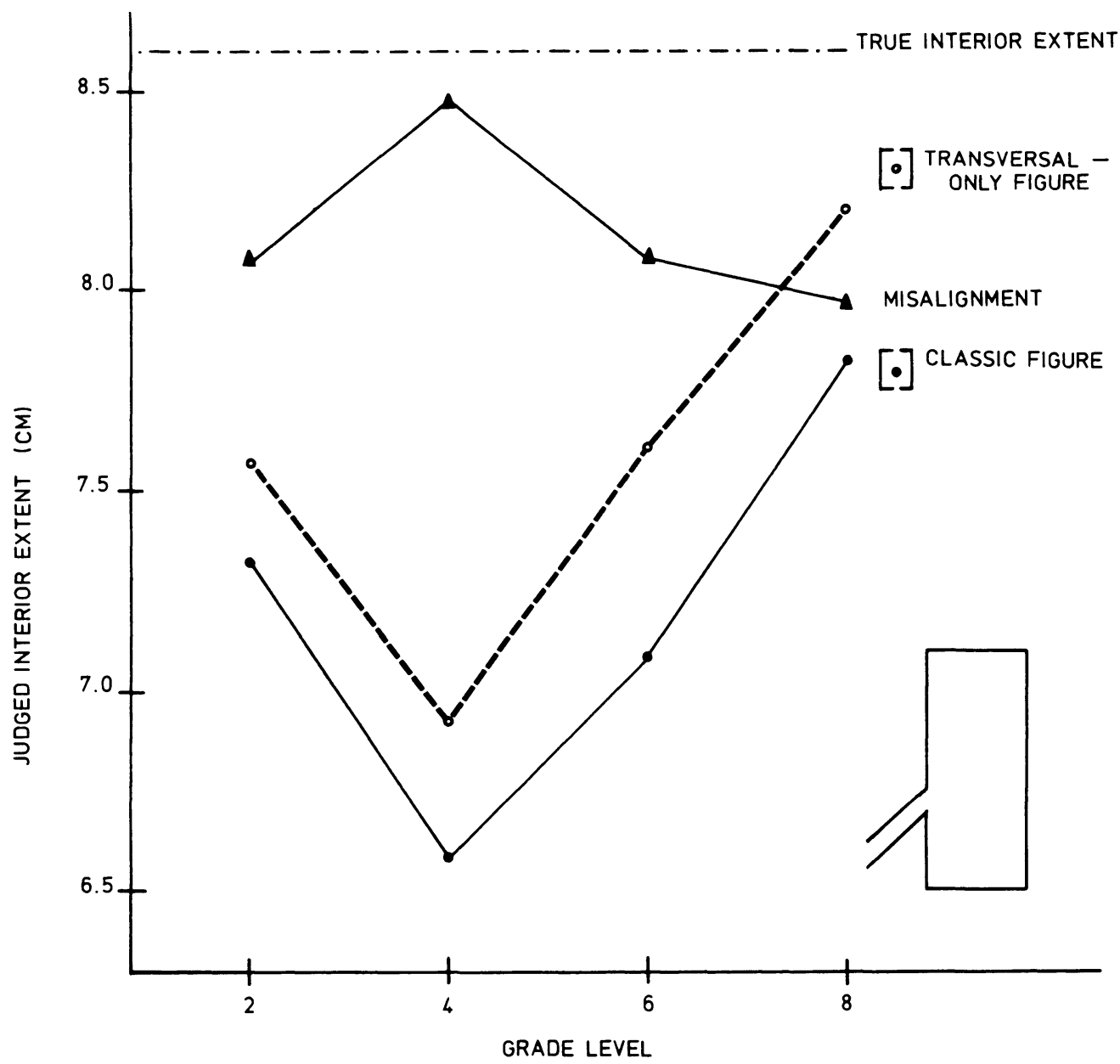

Figure 2. Experiment 2: age trends in mean judged extent for the classic Poggendorff figure and the transversalonly control figure. For comparison, mean judged extent found for college students (Greist-Bousquet \& Schiffman, 1981) is provided in brackets for the two figures. Also shown is Poggendorff misalignment presented as mean intertransversal extent judgments as a function of grade level.

dren's increasing knowledge of task requirements. This suggestion finds support in the present observation of large variability in illusion measures.

It is obvious that inconsistent age trends for visual illusions are important since they impact on theories of perceptual development. Inconsistent age trends for versions of the same illusion are of interest since they may indicate that there are different illusory processes operating within the same illusion figure and these processes are not equivalent. Unfortunately, inconsistent age trends for visual illusions due to changes in task ability or task understanding are not very interesting in this context.

\section{REFERENCES}

Girgus, J. S., \& CoREN, S. (1987). The interaction between stimulus variations and age trends in the Poggendorff illusion. Perception \& Psychophysics, 41, 60-66.

Greist-Bousquet, S., \& SChiffman, H. R. (1981). The Poggendorff illusion: An illusion of linear extent? Perception, 10, 155-164.
Greist-Bousquet, S., \& SChiffman, H. R. (1985). Poggendorff and Müller-Lyer illusions: Common effects. Perception, 14, 427-447. Greist-Bousquet, S., \& SChiffman, H. R. (1986). The basis of the Poggendorff effect: An additional clue for Day and Kasperczyk. Perception \& Psychophysics, 39, 447-448.

JudD, C. H. (1899). A study of geometrical illusions. Psychological Review, 6, 241-261.

LEIBOwITZ, H. W., \& GWOZDECKI, J. (1967). The magnitude of the Poggendorff illusion as a function of age. Child Development, 38, 573-580.

Pressey, A. W. (1971). An extension of assimilation theory to illusions of size, area, and direction. Perception \& Psychophysics, 9 , 172-176.

Quina-Holland, K. (1977). Spatial distortions within the Poggendorff figure and its variants: A parametric analysis. Perception \& Psychophysics, 21, 118-124.

Weintraub, D. J., \& Tong, L. (1974). Assessing Poggendorff effects via collinearity, perpendicularity, parallelism, and Oppel (distance) experiments. Perception \& Psychophysics, 16, 213-221.

Zanutrini, L. (1976). A new explanation for the Poggendorff illusion. Perception \& Psychophysics, 20, 29-32.

(Manuscript received for publication March 25, 1987.) 